\title{
Juventudes e ensino médio: direitos humanos e ensino para a diversidade
}

\author{
Youth and high school: human rights and education for diversity
}

\author{
Lia Machado Fiuza Fialho* \\ Francisca Genifer Andrade de Sousa** \\ Tânia Maria Rodrigues Lopes***
}

\section{Resumo}

Este artigo visa compreender os conhecimentos de educadores do ensino médio concernentes aos direitos humanos e à diversidade, bem como as práticas educativas que envolvem essa temática com vistas à formação cidadã das juventudes, público estritamente marcado pela heterogeneidade. Para atender aos objetivos, realiza-se uma pesquisa de caráter qualitativo do tipo estudo de caso com oito docentes do ensino médio público do Ceará selecionados aleatoriamente. A metodologia consiste na história oral temática, sendo os dados coletados mediante entrevistas híbridas - gravadas, transcritas, textualizadas e validadas - complementadas com o diário de campo. Constata-se que os professores não costumam associar tais construtos à prática docente, resultado possivelmente da ausência da discussão dessa temática na formação inicial e da inexistência de formação continuada. Além de escassas, quando há menção a respeito às diferenças, tolerância e condutas pacíficas, a abordagem é insuficiente, dada a carência de materiais didáticos e o pouco realce pelos currículos quanto à abordagem desses temas em sala de aula. Evidencia-se que, apesar das situações conflituosas entre os jovens, não há formação em direitos humanos, pois a docência desenvolvida pelos educadores do ensino médio enfatiza os conteúdos livrescos e a preparação para o Exame Nacional do Ensino Médio.

Palavras-chave: Direitos humanos. Diversidade. Juventudes.

Recebido em 05/03/2018 - Aprovado em 18/09/2018

http://dx.doi.org/10.5335/rep.v26i1.8110

Doutora em Educação Brasileira pela Universidade Federal do Ceará, com pós-doutorado em Educação na Universidade Federal da Paraíba (UFPB). Professora adjunta do Centro de Educação da Universidade Estadual do Ceará (UECE). Professora permanente do Programa de Pós-Graduação em Educação (PPGE) e do Mestrado Profissional em Planejamento e Políticas Públicas da UECE. E-mail: lia_fialho@yahoo.com.br

** Mestranda em Educação no PPGE da UECE. Graduada em Pedagogia pela UECE (2017). Pesquisadora do grupo de pesquisa Práticas Educativas Memórias e Oralidades da UECE. Bolsista Funcap. E-mail: geniferandrade@yahoo.com.br

*** Doutora em Educação Brasileira pela Universidade Federal do Ceará (2015), com pós-doutorado em Educação na UFPB (2016/2017). Professora adjunta da UECE. E-mail: tania.lopes@uece.br 


\section{Abstract}

This article aims to understand the knowledge of high school educators concerning human rights and diversity as well as the educational practices that involve this issue with a view to citizen youth training, a public that is strictly marked by heterogeneity. To meet the objectives, a qualitative research of the case study type is carried out with eight randomly selected teachers from public secondary education in Ceará. The methodology consists of thematic oral history, the data being collected through hybrid interviews - recorded, transcribed, textualized and validated - complemented with the field diary. It is observed that teachers do not usually associate such constructs with the teaching practice, possibly resulting from the absence of the discussion of this subject in the initial formation and the inexistence of continuous formation. Besides being scarce, when diferences are mentioned and so are tolerance and peaceful conduct, the approach is insufficient, given the lack of teaching materials and the lack of emphasis by the curricula towards the approach of these themes in classroom. It is evident that, despite conflicting situations among young people, there is no training in human rights, since teaching developed by high school educators emphasizes textbook contents and preparation for the High School National Exam.

Keywords: Human rights. Diversity. Youth.

\section{Introdução}

Partindo da compreensão de que a escola assume o compromisso de formar o cidadão nos seus múltiplos aspectos e de que inclusive tal dever é amparado por leis - tais como os Parâmetros Curriculares Nacionais (PCNs) e a Lei de Diretrizes e Bases da Educação Nacional (LDB) -, o propósito deste estudo é discorrer sobre direitos humanos e ensino para a diversidade no ensino médio.

Nesse sentido, desenvolveu-se uma pesquisa com professores que lecionam no ensino médio do estado do Ceará entre janeiro e março de 2018. O estudo apoiou-se na análise e na interpretação de entrevistas realizadas com os docentes, objetivando investigar as suas compreensões sobre direitos humanos e diversidade, bem como se há o ensino dessas temáticas e, em caso positivo, como é desenvolvido com as juventudes em meio aos conteúdos curriculares do ensino médio.

A formação para a cidadania e para o respeito à diversidade atrelada ao ensino dos conteúdos curriculares é também um dever da escola a ser consolidado pela prática da Educação em Direitos Humanos (EDH) (MARQUES, 2012). Na visão de Magri (2012), a EDH tem o objetivo de despertar nas pessoas a percepção dos direitos de si e do próximo, culminando, assim, na formação cidadã do indivíduo.

A formação cidadã do indivíduo acontece por meio da escolarização formal aquela desenvolvida nos espaços institucionalizados - e também por meio da educação informal, que abarca toda a vivência social. Destarte, é essencial repensar o papel da escola nessa missão. Para Silva (1997), a escola deve cumprir com o seu dever, pois ela é espaço privilegiado para a formação cidadã, devendo ter a EDH como objetivo global, contínuo e permanente, sendo essencial a “[...] construção de 
um projeto pedagógico democrático e participativo, no qual a formação do sujeito possa ser assumida coletivamente" (1997, p. 220-221).

Considerando as práticas educativas em desenvolvimento, prioritariamente nos anos finais da educação básica, que antecedem o Exame Nacional do Ensino Médio (Enem), cujo centro do processo é o ensino por competências e o domínio de conteúdos, chegou-se ao seguinte problema: como os professores do ensino médio trabalham os direitos humanos e a diversidade com as juventudes? Levantou-se a hipótese de que atitudes como preconceito, discriminação e intolerância, que emergem corriqueiramente entre os jovens, público fortemente marcado pela diversidade, são silenciadas pelos professores, possivelmente em decorrência da falta de conhecimentos dos docentes e da invisibilidade dessas temáticas no cotidiano escolar.

Revelar as consistências e as contradições no trato pelos educadores e pelos sistemas de ensino no que diz respeito aos direitos humanos e à diversidade bem como analisar o modo como as suas práticas interferem na formação cidadã das juventudes motivaram o desenvolvimento desta pesquisa, visto que o modelo de educação historicamente enraizado é resultado das permanências pedagógicas.

Importa esclarecer que a noção de direitos humanos é contemporânea (SACAVINO, 2011), tendo surgido em concomitância com a modernidade. Em 1993, a Conferência de Viena, organizada pela Organização das Nações Unidas (ONU), incentivou os países a formularem um sistema educacional que tratasse os direitos humanos com vistas a clarear a sua constituição para a sociedade civil, de modo a formar um cidadão ciente de suas responsabilidades e apto a enfrentar os problemas de violação dos seus direitos políticos, econômicos, civis e culturais, assim como a combater a intolerância. Em nível nacional, pode-se considerar que tal medida foi tomada em 2003, com a criação do Comitê Nacional de Educação em Direitos Humanos (CNEDH), cujo objetivo foi planejar um documento que abordasse as políticas, as ações e os programas voltados ao respeito aos direitos humanos.

Mais tarde, em 2010, a Conferência Nacional de Educação (Conae) voltou a abordar o tema, chamando a atenção para o fato de a EDH vir ocupando cada vez mais espaço no cenário educacional brasileiro. $\mathrm{Na}$ ocasião, as temáticas inclusão, diversidade e igualdade foram destacadas e consideradas emergentes.

Em 2012, as Diretrizes Nacionais para a Educação em Direitos Humanos (DNEDH) foram aprovadas por meio do Parecer $\mathrm{n}^{\circ}$ 8, do Conselho Nacional de Educação (BRASIL, 2012). Tais diretrizes consideraram como princípios a serem prezados pela educação: a dignidade humana, a igualdade de direitos e a valorização das diferenças, a sustentabilidade ambiental, a laicidade por parte do Estado, a transversalidade, a vivência e a globalidade. Com relação à sua efetivação nas escolas, foi asseverado que "[...] a inserção dos conhecimentos concernentes à educação 
em direitos humanos nos currículos poderá se efetivar [...] pela transversalidade de temas tratados interdisciplinarmente, como conteúdo específico de disciplina já existente ou de maneira mista [...]" (MENDONÇA, 2013, p. 259).

De acordo com Magendzo (2006), a intenção da EDH deve ser formar o indivíduo integral, englobando todas as suas dimensões: instruindo-o na luta pelos seus direitos, na obediência aos seus deveres e no desenvolvimento da plena cidadania. Assim, o sujeito formado nesse âmbito será capaz de lutar contra as desigualdades e as injustiças sociais, enxergando os demais como indivíduos de iguais direitos e valorizando a harmonia e a tolerância perante a diversidade.

\section{Metodologia}

Optou-se pela abordagem qualitativa nesta pesquisa, dada a indispensabilidade de realização de um estudo que viabilizasse problematizar as compreensões e as práticas educativas de professores do ensino médio referentes ao tratamento das temáticas "direitos humanos" e "diversidade" como conteúdos formativos das juventudes estudantes do referido nível de escolaridade. O estudo se apoiou na análise e na interpretação dos dados adquiridos mediante entrevista realizada com oito docentes do ensino médio do estado do Ceará, os quais foram selecionados aleatoriamente para participar da pesquisa.

Ao todo, foram abordados 13 professores de ensino médio escolhidos aleatoriamente, mas somente 8 demonstraram interesse em colaborar com as entrevistas, pois 3 alegaram falta de tempo para responder aos questionamentos e 2, ao serem informados acerca da temática, recusaram-se a participar, argumentando desinteresse em falar sobre o assunto. Os professores participantes da pesquisa atuavam em instituições públicas da cidade de Fortaleza - capital do Ceará - e de outros dois municípios situados na região metropolitana de Fortaleza: Beberibe e Pindoretama, sendo 4 de Fortaleza, 3 de Pindoretama e 1 de Beberibe. Dentre os educadores, 5 eram do sexo feminino e 3 do sexo masculino, com idade média de 35,3 anos; desses, 6 dedicavam-se somente a uma escola e 2 dedicavam-se a mais de uma, sendo 5 vinculados por meio de concurso e 3 por contrato temporário.

O termo de consentimento assinado pelos docentes, além de explicitar o tema, o objetivo e os detalhes da forma de participação e divulgação dos resultados, também assegurava o anonimato aos envolvidos. Por isso, os seus nomes foram substituídos pelas seguintes abreviações: D1 (professor de Matemática, 8 anos de ensino médio); D2 (professora de Inglês e de Português, 3 anos de ensino médio); D3 (professor de História e de Sociologia, 5 anos de ensino médio); D4 (professora de Educação Física, 4 anos de ensino médio); D5 (professora de Português, 2 anos 
de ensino médio); D6 (professor de Geografia, 12 anos de ensino médio); D7 (professora de Biologia, 7 anos de ensino médio); e D8 (professora de Química, 8 anos de ensino médio).

Considerando as minúcias que o estudo se propôs a discutir, a história oral temática híbrida (MEIHY; HOLANDA, 2007) foi o percurso metodológico mais adequado, considerando a viabilidade de compreensão contextualizada a partir dos discursos dos professores, dos conhecimentos e das práticas por eles desenvolvidas no desenrolar da docência com relação à diversidade e aos direitos humanos. Importa destacar que o diário de campo foi utilizado como recurso complementar às entrevistas, para o registro de outras peculiaridades, como: as percepções pessoais implícitas na fisionomia, o número de professores abordados em cada instituição e o registro de justificativas no caso dos que se negaram a participar da entrevista.

As entrevistas foram gravadas, transcritas na íntegra, textualizadas e validadas, seguindo a técnica de estrutura geradora do discurso (FLICK, 2009). Utilizaram-se quatro pontos temáticos para discussão: "1) O que você entende por direitos humanos?"; "2) O que você entende por diversidade?"; "3) No ensino de sua disciplina, você aborda estas temáticas: direitos humanos e diversidade? Justifique"; e "4) Em caso positivo, qual metodologia você utiliza para trabalhar essas temáticas?".

Seguindo os ensinamentos de Bardin (2009), os resultados oriundos da coleta de dados foram submetidos à análise de conteúdo, o que permitiu desvendar significações das narrativas com base na inferência ou na dedução, seguindo as três fases seguintes: pré-análise; exploração do material e tratamento dos resultados; e inferência e interpretação.

Na pré-análise, as ideias iniciais foram condensadas para posterior interpretação das informações. $\mathrm{Na}$ fase posterior, foi realizada a exploração do material com base na leitura e na releitura detalhadas das transcrições. Por fim, no tratamento e na interpretação dos resultados, todas as falas foram divididas em grupos temáticos e categorizadas, reunindo-se as respostas afins. Como resultado desse procedimento, emergiram três categorias: 1) compreensões docentes sobre direitos humanos e diversidade; 2) práticas pedagógicas no ensino em direitos humanos e diversidade; e 3) currículo e formação do professor na educação para diversidade e direitos humanos.

\section{Resultados e discussão}

O acesso à escola é um direito humano formulado no século XIX, tendo tomado impulso prioritariamente nos anos finais do século XX e início do século XXI, por meio de políticas educacionais que defendem a universalidade da educação básica 
(HADDAD, 2004). A ampliação dos sistemas de ensino tornou mais visível a diversidade de grupos sociais e culturais, reforçando a heterogeneidade dos que frequentam a escola, "[...] particularmente de determinados sujeitos e grupos, colocando no centro dos debates e das preocupações a questão da qualidade da educação" (CANDAU, 2012, p. 721).

Importa, pois, compreender a diversidade como fruto dos processos econômicos, políticos, históricos e culturais, inter-relacionados, como construção social, e não como problema a ser superado. É a partir desse entendimento que a sociedade, também por intermédio das políticas públicas e educacionais, começa a ensejar abertura para a diversidade em seus discursos e planos de ação, como é o caso da EDH (GOMES, 2012). A valia da EDH pode ser constatada pela ONU, mediante documentos legais, e pelo Programa Mundial para a Educação em Direitos Humanos, criado em 2004. Com relação ao referido programa, a educação deve:

a) criar uma cultura universal dos direitos humanos; b) exercitar o respeito, tolerância, promoção e valorização da diversidade religiosa, de gênero, de orientação sexual e cultural, e a amizade entre as nações, povos indígenas e grupos étnico-raciais; c) possibilitar a todas as pessoas terem acesso à participação efetiva em uma sociedade livre (BRASIL, 2007, p. 25).

Considerando o panorama da sociedade atual, demasiadamente marcado pela intolerância e pela violência (física e verbal), e a diversidade que abrange principalmente o público juvenil, a EDH vem a ser "[...] um dos mais importantes instrumentos dentro das formas de combate às violações de direitos humanos, já que educa na tolerância, na valorização da dignidade e nos princípios democráticos" (TAVARES, 2007, p. 487).

Embora a EDH seja recorrentemente discutida na atualidade, este campo de atuação é recente no que tange ao cenário não somente brasileiro, mas também latino-americano. No Brasil, destacam-se documentos legais que, de fato, integram a educação formal à EDH, como a Constituição federal de 1988 (BRASIL, 1988) e a LDB de 1996 (BRASIL, 1996).

Por meio da EDH, os indivíduos são estimulados a enxergar a si e ao próximo como cidadãos de direitos, sendo a escola um espaço de efetivação e de construção da democracia. Tal instituição assume papel fundamental, já que, como promotora dos direitos humanos, deve prezar pelas discussões formativas do cidadão sem discriminação de sexo, etnia, classe social, escolarização e faixa etária, haja vista que os direitos humanos são concedidos para todos, independentemente de qualquer distinção e nação (FRANCESCHINI; SILVA; MARQUES, 2017). Tratam-se de direitos para a humanidade de modo universal, não sendo, portanto, fruto de um país - e nem a ele restrito -, mas construído pela humanidade para a humanidade. 
De acordo com Santos e Nunes (2003), os direitos humanos nos dão uma ideia de união, pois tornam todos importantes e iguais, apesar da diversidade.

Consoante Giddens (1991), a função social da escola é proporcionar aos alunos a formação necessária para a convivência com a diversidade, que abarca não somente o espaço educativo, mas todo o âmbito social. $\mathrm{O}$ autor destaca inúmeros desafios, mas reconhece que a escola é local privilegiado para travar essa luta por ser espaço de heterogeneidade e de diversidade em variados aspectos. Em congruência com esse pensamento, Candau afirma que "[...] a escola deveria exercer um papel de humanização a partir da socialização e da construção de conhecimentos e de valores necessários à conquista do exercício pleno da cidadania” (1996, p. 14-15).

Para Tavares, é urgente a atuação das escolas brasileiras na disseminação dos direitos humanos como cultura na sociedade, tendo em vista que "[...] os fortes traços do colonialismo e da escravidão, presentes durante vários séculos, ainda encontram ressonância e alimentam o autoritarismo, a discriminação, a exclusão e o preconceito atuais" (2007, p. 492). Somente por esse rumo, quando os direitos humanos se tornarem cultura, é que teremos uma sociedade justa e que priorize o ser humano e a vivência democrática e cidadã.

Discutir sobre direitos humanos e diversidade nas escolas, prioritariamente com as juventudes, público que vivencia as diferenças ainda mais acentuadas, implica perceber o ser humano em suas múltiplas dimensões. É reconhecer que nem todos são iguais, embora a diferença e a diversidade sejam, muitas vezes, ignoradas, como é o caso das distinções de etnia, gênero, orientação sexual, religião e classe social, que nos últimos tempos têm causado conflitos e, mesmo assim, não são enfatizadas como se deveria nas escolas.

\section{Diversidade juvenil}

A juventude passou a ser caracterizada como uma fase da vida inevitável que demarca o período de transição entre a infância e a vida adulta. São muitos os estudiosos que definem o termo "juventude" de diferentes maneiras: "[...] como uma faixa etária, um período da vida, um contingente populacional, uma categoria social, uma geração" (ABRAMO; LEÓN, 2005, p. 6).

Para o Estatuto da Juventude e para a Política Nacional de Juventude (PNJ), são jovens aqueles com idade entre 15 e 29 anos, sendo que a Política Nacional de Juventude divide essa faixa etária em três grupos: "[...] jovens da faixa etária de 15 a 17 anos, denominados jovens-adolescentes; jovens de 18 a 24 anos, como jovens-jovens; e jovens da faixa de 25 a 29 anos, como jovens-adultos" (SILVA; SILVA, 2011, p. 664). Já para a Organização das Nações Unidas para a Educação, a Ciên- 
cia e a Cultura (UNESCO) (1998) e para a Organização Mundial da Saúde (OMS) (2010), são jovens os indivíduos com idade entre 15 e 24 anos.

No entanto, segundo Batista, "[...] esta conceituação, tendo como referência a faixa etária, não parece suficiente para tratar de categoria cuja complexidade se mostra volumosa" (2009, p. 6962). O autor ressalta ainda que "[...] há muitas outras formas de conceituar a juventude, lançando mão de aspectos sociais, culturais ou legais, entre outros de igual relevância, respeitando uma diversidade de contextos e realidades" (2009, p. 6962).

Assim sendo, pode-se compreender que juventude não se limita a uma fase de transição inerente ao homem. Nesse grupo, há jovens com identidades distintas, o que permite formular o conceito de juventudes (no plural), considerando a diversidade e as individualidades que permeiam os seus integrantes a partir dos construtos históricos e culturais, visto que, "[...] apesar de ter por base marcos etários e biológicos, a definição da população jovem é indissociável do contexto sociocultural, político e econômico" (BRASIL, 2010, p. 15).

Os autores consultados na produção deste estudo - e que apoiam as análises apresentadas - apontam que são muitos os fatores que corroboram a compreensão e a definição da juventude. Assim, torna-se impossível generalizar essa fase considerando as características e as manifestações externas, muito menos interpretá-la de maneira hegemônica, uma vez que ela não é somente uma fase de transição, mas contempla complexidades variantes (FIALHO, 2015).

Sob esse viés, a juventude se apresenta como mais do que uma simples fase de transição entre a infância e a vida adulta. Ela está diretamente relacionada à época, à cultura e ao ambiente a que o indivíduo pertence. Como assinala Batista: "É a partir desse pressuposto que se propõe a abordagem da juventude em seu plural, juventudes, numa leitura que enfatiza a diversidade de modos de ser jovem existente" (2009, p. 6964).

Essa diversidade que abrange o público juvenil e suas particularidades em relação aos demais indivíduos é apontada como uma das características que fazem com que esse segmento seja considerado alvo de investimentos específicos, haja vista que:

Mesmo diante da diversidade de experiências abarcadas pelo termo 'juventude', há uma série de fatores que justificam a proteção, a promoção e a efetivação de direitos específicos, por meio de políticas públicas, considerando que se trata de um segmento com características e necessidades próprias, compartilhadas entre si e distintas das de outros grupos na sociedade [...] (BRASIL, 2010, p. 15-16).

De acordo com o Fundo de População das Nações Unidas (UNFPA), “[...] embora a população jovem tenha necessidades singulares e seja considerada objeto de 
grande importância na formação dos futuros líderes, esta faixa etária foi negligenciada durante anos" (2011, p. 20). Seguindo o mesmo raciocínio, Araújo afirma que, “[...] no que se refere especificamente à juventude brasileira, não existiu para esse público, até os anos 90, políticas direcionadas, sendo assim esquecidas por parte do Estado" (2014, p. 6).

O cenário anteriormente caracterizado, de negligência para com as especificidades das juventudes, só passou a mudar no final da década de 1990 e no início do século atual, época em que o ensino em direitos humanos ganhou força nos discursos públicos. Na prática, em contraponto, apesar das diversidades juvenis e da emergência de se abordar tal construto na formação dos jovens, a temática apresenta-se tímida, o que pode ser evidenciado ao analisar os projetos e programas voltados a essa temática desenvolvidos pelo sistema público de ensino (MENDONÇA, 2013).

\section{Categoria 1: compreensões docentes sobre direitos humanos e diversidade}

Todos os docentes discorreram sobre o significado de direitos humanos; em sua maioria, as compreensões apontaram para o real significado do termo. Em alguns casos, as respostas apresentaram-se de modo superficial, mas, mesmo assim, evidenciaram coerência, como nos dois casos a seguir: "São direitos de todos, de todos que se enquadram na categoria ser humano" (D4); "Ah, são os direitos que a gente tem. Todos nós, eu, você e todos os cidadãos livres. É o direito à vida, à liberdade de expressão, à saúde, à moradia" (D2).

D5, que lecionava Português no ensino médio havia 2 anos, assumiu não ter compreensão aprofundada sobre direitos humanos, o que, para ela, era uma deficiência de sua formação superior. Todavia, mesmo diante de tal dificuldade, ela buscou conceituar direitos humanos a partir do seu conhecimento de mundo, verbalizando um argumento também relevante para este estudo:

O que eu entendo de direitos humanos... É... Uma compreensão subjetiva [pausa]. A compreensão que eu tenho de direitos humanos é que ela é formada e também eu posso dizer que é difícil falar disso. Eu vou ter como base a minha atuação básica, a minha formação no Ensino Superior, em que eu não aprendi a fundo no que se refere do que tratam esses direitos humanos. E o que eu entendo de direitos humanos é que eles garantem que o sujeito seja pertencente do espaço onde ele percorre, onde ele caminha, onde ele vive, por onde ele passa [...]. O que eu entendo de direitos humanos é isso, ele garante o respeito, a solidariedade, por saber que cada sujeito tem a sua história, que cada sujeito tem o direito de ser livre, de ser quem ele quiser ser (D5).

Outros docentes demonstraram mais precisão e clareza, discutindo suas respostas: 
Direito é aquilo que todos devemos ter, independentemente de cor, de raça, de classe social ou de sexo. É o direito de ter um local para morar, direito de votar, direito de se expressar, direito de estudar. Aí direitos humanos são todos esses direitos que eu falei e que devem ser garantidos para todos (D3).

Direitos humanos... É como o próprio nome já diz, né? É o direito humano [risos]. É o direito de a gente ter a liberdade, a igualdade, a educação, a saúde, a segurança. Embora, às vezes, a gente não tenha, mas é o direito da gente. É um direito de todos, não importa se é rico, se é pobre, se é negro, se é branco, se é amarelo. É um direito assegurado por lei e pronto (D6).

Em seu sentido mais básico, direito trata de uma exigência justificada de um indivíduo ou grupo feita a outros. Por conseguinte, direitos humanos consistem naqueles que são "[...] mantido[s] por todos os seres humanos e apenas por seres humanos, e não depende[m] de cidadania nacional ou qualquer outro atributo" (MCCOWAN, 2015, p. 28). Tal como foi verbalizado por D3, os direitos humanos "[...] fornecem proteções fundamentais para indivíduos e grupos e asseguram as condições para a prosperidade humana" (MCCOWAN, 2015, p. 29), como os direitos à vida, à liberdade de opinião e de expressão, ao trabalho e à educação.

De modo semelhante, D1, professor de Matemática com 8 anos de ensino médio, disse que direitos humanos representam aqueles comuns a todos os seres humanos, a serem garantidos pelo Estado; o educador completou afirmando que são conquistas adquiridas por meio da luta, sendo necessária a mobilização com vistas a garantir outros direitos:

É o direito comum a todos os seres humanos, os direitos básicos à vida de todos nós, como ir e vir [pausa]. É ter todas as necessidades assistidas pelo poder público, como educação, saúde, segurança. São esses os direitos humanos que eu entendo que são conquistas da gente, e a gente tem que lutar por mais (D1).

Nem sempre existiram mecanismos de proteção aos direitos humanos (BASOMBRIO, 1992), eles são frutos de muitas lutas pela dignidade humana para todos igualmente (RAMOS, 2011). Não se trata, portanto, de um construto que surgiu em decorrência da modernidade, mas a partir da construção e da conquista, que devem ser permanentes, pois nem todos os direitos surgiram de uma só vez, sendo necessária constante atualização. Essa preocupação chama a atenção para o papel dos processos educativos, que devem ser veículos de aperfeiçoamento, conforme destacado pela Assembleia Geral da ONU ainda em 1948, ao se referir à escola como promotora do respeito aos direitos e da liberdade, ideal que deveria ser comum a todos os povos e nações.

Assim como nas compreensões de diversidade, de modo geral, as respostas foram bem semelhantes quando o assunto referiu-se aos direitos humanos, pois houve definições breves e superficiais, como a de D1: "São as diferenças. É aquilo que 
é diverso, por exemplo: temos a diversidade de plantas, de animais, de moradias... e de pessoas”. Entretanto, em outras situações, foi possível coletar informações mais elaboradas acerca do significado de diversidade. Dentre essas, as que tiveram maior número de recorrência foram as que pontuaram sobre a diversidade humana, realçando características externas, crenças, modos de pensar e de se comportar.

No meu contexto, considerando a minha vida particular e profissional, diversidade é a diferença entre mim e os meus irmãos: eu, loira de olho azul, e um irmão negro; é aqui na escola, quando eu chego e vejo os 'emos', os góticos, os 'gays' [pausa], porque todos têm o direito de escolher como querem viver. É tanta coisa (D2).

De acordo com os meus estudos, são as diferenças. É a diversidade de cor da pele, de religião e de crença, de sexualidade, de comportamentos. Diversidade é tudo isso, tudo o que é diverso (D3).

Em congruência com os discursos anteriores, que versaram sobre diversidade considerando aspectos para além das características biológicas, Gomes (2007) afirma que a diversidade é histórica, cultural e social, não podendo realmente ficar restrita ao aspecto biológico e natural do indivíduo.

A diversidade é muito mais do que o conjunto das diferenças. Ao entrarmos nesse campo, estamos lidando com a construção histórica, social e cultural das diferenças [...]. Portanto, ao falarmos sobre a diversidade (biológica e cultural), não podemos desconsiderar a construção das identidades, o contexto das desigualdades e das lutas sociais (GOMES, 2007, p. 41).

D5, professora de Português com 2 anos de ensino médio, chamou a atenção para a importância da diferença, compreendida como a comunhão na divergência. Ela destacou que a diversidade faz-se necessária para o desenvolvimento da sociedade:

A diversidade proporciona a unidade na diferença. Então, a diversidade é isso, é a comunhão na divergência. Eu digo que a diversidade é dialética, porque a partir dessa divergência é que surge uma nova maneira de pensar, uma nova maneira de compreender o outro, de entender o outro. Porque, se todas as pessoas fossem iguais, eu acredito que o nosso país, que a nossa sociedade não se desenvolveria (D5).

É nessa perspectiva que a diversidade é compreendida como ampla, dinâmica e repleta de atributos variados, como etnia, gênero, religião, cor da pele, nacionalidade, valor, cultura e tantos outros aspectos. "Essas diferenças, a rigor, compõem o quadro de riqueza humana constitutiva de uma sociedade multifacetada [...]" (MENDONÇA, 2013, p. 256). 


\section{Categoria 2: práticas pedagógicas no ensino em direitos humanos e diversidade}

Do total de 8 docentes, 4 afirmaram não discutir sobre direitos humanos e diversidade; 2 manifestaram buscar trazer a temática para discussão, mas indicaram não ter certeza se conseguiriam de fato; e 2 declararam abordar a temática sempre que possível. Em suma, metade dos professores entrevistados pontuou que suscitava os direitos humanos e a diversidade como assuntos de suas aulas. No entanto, ao serem indagados sobre a metodologia adotada, os quatro disseram ser apenas uma orientação verbal em sala de aula.

Não sei se é bem uma metodologia. A gente discutiu umas duas ou três vezes porque foi preciso. Tinha um aluno sofrendo 'bullying' por ser mais afeminado, sabe, aí problematizamos isso (D2).

É a discussão mesmo. Nem chega a ser exposição porque nem material didático tem! E nem discussão também porque é eu falando e um aluno vai abrindo a boca aqui e outro acolá. Entendeu? É mais um monólogo, que eu nem sei se serve para alguma coisa. Só Deus sabe (D3).

É a conversa mesmo. Os exemplos que a gente tem da própria vida, das experiências com quem convive com a gente... É isso, só falando mesmo (D4).

Para Nascimento (2000), a prática pedagógica deve articular os conhecimentos em direitos humanos com a participação efetiva dos estudantes, de modo que possam pôr em prática ações coletivas e que desenvolvam a capacidade de tomar decisão, pois, desse modo, há "[...] a possibilidade de aprofundar a consciência de sua própria dignidade, a capacidade de reconhecer o outro, de vivenciar a solidariedade, a partilha, a igualdade na diferença e a liberdade" (NASCIMENTO, 2000, p. 121).

Esse modelo de prática, com efeito, ultrapassa a mera discussão oral realizada pelos professores e promove a inserção do individual no coletivo, já que amplia as possibilidades de participação de todos nas tomadas de decisão social, prioritariamente de grupos excluídos, atuando rumo aos processos de democratização e de transformação (SACAVINO, 2000).

Comunga-se com Morgado (2002) ao compreender-se que a prática pedagógica na EDH deve ser pautada em três saberes a serem dominados pelo educador saber curricular, saber pedagógico e saber experiencial. O saber curricular deve ser flexível, a fim de viabilizar o ensino sobre direitos humanos de acordo com o contexto social, cultural e histórico. O saber pedagógico se relaciona com o método a ser adotado para a articulação dos conteúdos curriculares com a EDH. Já o saber 
experiencial enfatiza a prática desses direitos, analisando a sua promoção e os mecanismos de luta por eles.

Desse modo, é válido trabalhar com uma metodologia que associe esses três saberes, de forma a proporcionar a percepção e a análise crítica da realidade em que os indivíduos estão inseridos, priorizando a metodologia ativa e participativa, visto que é um cidadão participativo que se quer formar, o que torna insipiente a mera orientação verbal realizada pelos professores entrevistados.

D5 atuava então no ensino médio, mas antes havia trabalhado com crianças, por ser pedagoga. Ela indicou que discutir essas temáticas era necessário, porém manifestou que nunca havia conseguido trazê-las à tona com os jovens, somente com as crianças pequenas. Também para ela, a metodologia a ser adotada seria a discussão:

Assim, aqui eu nunca trabalhei com isso, não. Eu já trabalhei com as crianças menores de 04 e 05 anos, porque também sou pedagoga, né? Mas faz pouco tempo que estou aqui e eu vejo que é mais complicado falar sobre isso com os alunos maiores. Eu tento trazer o assunto para discussão, tento conversar com eles [pausa]. Eu vejo que é importante e pretendo, mas até agora não deu certo (D5).

No discurso anterior, entende-se que a formação voltada aos direitos humanos é irrefutável, mas que esta é uma tarefa difícil de ser executada com os alunos do ensino médio, diferentemente do que acontece com os discentes da educação infantil, por exemplo. Para D2, é muito importante formar para o respeito às diferenças, todavia, a grande dificuldade radica-se na ausência de materiais didáticos, o que culmina em uma prática puramente voltada à discussão/exposição por parte do educador: "Não tinha material didático nem nada, a gente só discute em grupo mesmo e tenta conscientizá-los para o respeito com o outro, para aceitar as diferenças entre eles mesmos. E isto é um direito de todos: ser respeitado, mas também tem que respeitar" (D2).

Em conformidade com Mendonça (2013), ao tratar da EDH, não basta transmitir conhecimentos sobre os direitos. Em lugar da exposição verbal, deve haver lugar para o diálogo e o exercício prático, caso contrário:

Esse tipo de estratégias atua fundamentalmente no plano cognitivo, quando muito oferece informações, ideias e conceitos atualizados, mas não leva em consideração as histórias de vida e experiências dos participantes e dificilmente colabora para a mudança de atitudes, comportamentos e mentalidades. Em geral, no melhor dos casos, propicia espaços de sensibilização e motivação para as questões de Direitos Humanos, mas seu caráter propriamente formativo é muito frágil (CANDAU, 2008, p. 291).

Para isso, fazem-se necessárias a postura e a vontade própria do professor, mas especialmente a formação pedagógica, dado que: 
A EDH (educação em direitos humanos) requer uma metodologia, com a seleção e organização dos conteúdos e atividades, materiais e recursos didáticos que sejam condizentes com a finalidade de um processo educativo em direitos humanos. Estes requisitos são essenciais para que a prática pedagógica facilite a formação de uma consciência crítica e de um compromisso social com as questões relacionadas à problemática dos direitos humanos (TAVARES, 2007, p. 491-492).

D1, por sua vez, demonstrou-se confuso e acabou discorrendo sobre as diferenças que tratava ao abordar os conteúdos da sua disciplina (Matemática). Logo na sequência, ele percebeu que não seria esse o sentido de diferença questionada na pesquisa e confessou que, de fato, nunca havia mencionado sobre direitos humanos ou diversidade nas suas aulas, por compreender não ser de sua responsabilidade.

Direitos humanos eu nem me lembro de ter falado. De diferenças eu já falei com toda certeza: a diferença das medidas, dos tamanhos dos triângulos, essas coisas da Matemática [pausa]. Mas nem é esse tipo de diferença que é para eu falar, né? Agora que me liguei que o tipo de diferença que você quer saber deve ser de gênero, de cor, não é? Diferença entre as pessoas? Mas não, desses tipos de diferenças aí eu nunca falei, até porque eu sou professor de Matemática. Antigamente tinha o professor de Religião que falava sobre essas diferenças, de respeito, mas hoje eu não sei quem é que fala, não (D1).

Interessa salientar que a educação para diversidade e direitos humanos é transversal e perpassa todas as áreas do conhecimento, logo, o educador que trabalha com Ciências Exatas não está alheio a essa compreensão e a esse diálogo. Para a formação do indivíduo na condição de cidadão, faz-se mister atentar para as metodologias aplicadas e para a interdisciplinaridade, de sorte que a EDH seja desenvolvida em paralelo com os mais diversos conteúdos curriculares (GADOTTI, 1999).

Em congruência ao exposto, D3 afirmou que buscava polemizar tais questões no desenrolar dos conteúdos de sua disciplina e mostrou que há essa possibilidade na área de Ciências Humanas: "Nas aulas de Sociologia, nos debates, eu discuto, sim. Lá em John Locke, por exemplo, quando vamos estudar a questão da propriedade privada e do direito à vida, a gente discute sobre os direitos humanos [...]" (D3). O mesmo aconteceu com relação à diversidade, sendo que o educador enfatizou algumas temáticas por considerá-las mais pertinentes: “[...] diversidade eu falo sobre principalmente religião, cor de pele, e a questão da homossexualidade, porque são esses em que eu vejo mais necessidade [...]" (D3). Percebe-se que o docente destacou grupos específicos mais vulneráveis à discriminação em seu contexto de atuação.

Para a garantia dos direitos humanos, não são necessárias apenas políticas universais, mas também políticas específicas para os grupos historicamente vulneráveis e excluídos, uma vez que, "[...] ao lado do direito à igualdade, surge, também, como direito fundamental, o direito à diferença. Importa o respeito à diferença $\mathrm{e}$ 
à diversidade, o que lhes assegura um tratamento especial" (PIOVESAN, 2006, p. 24). Por meio dessa dualidade entre diferença e igualdade, a desigualdade será superada, ao mesmo tempo que se valoriza a diversidade e se promove o respeito para com elas, haja vista que "[...] os sujeitos de direitos são também diversos em raça, etnia, credo, gênero, orientação sexual e idade, entre outros" (GOMES, 2012, p. 688), e todas essas especificidades precisam ser consideradas inclusive pelos docentes e sistemas de ensino.

D2 assinalou ter sido necessário pausar o conteúdo de sua disciplina para se voltar à formação cidadã dos alunos, pois o contexto em que lecionava anteriormente era palco de conflitos, o que a instigou a mudar aquela situação, conforme versado pela docente:

Na minha disciplina em si, não. Não existe esse assunto em Inglês e Português. Mas já saí do assunto da minha aula para falar sobre essas coisas, como uma vez que tinha uma briga de gangues em uma escola em que eu trabalhava em Horizonte e os alunos estavam muito agitados por conta disso, com medo, com vontade de brigar, de se vingar, aí eu tentei fazer eles se acalmarem mais (D2).

De acordo com Soares (2016), o professor, ao interagir com os grupos sociais, tende a humanizar a ação docente, já que, ao apropriar-se da realidade social, é de sua natureza almejar ir além do fazer educativo e adentrar na esfera da formação para o mundo. Nessa perspectiva, outros dois docentes se posicionaram de modo semelhante à educadora anterior, partindo da necessidade diária de discutir determinados assuntos. No primeiro caso, chama-se a atenção para a valia do professor debater sobre diversidade e conscientizar os educandos sobre tolerância. No segundo, parte-se da compreensão da regularidade dos rótulos e dos estigmas e conclui-se que o educador pode ser crucial para a propagação do respeito e da paz:

$\mathrm{Na}$ escola em que eu trabalho, eu vejo que é bom falar de diversidade, conversar com os meus alunos, conscientizá-los, buscar fazer com que eles sejam mais tolerantes com o próximo que não é parecido com ele (D4).

Hoje a gente percebe muito facilmente, ou seja, é visível, é muito perceptível essa questão dos rótulos e dos estigmas, né? Infelizmente. Se a pessoa se comporta de uma forma, logo ela é taxada por apenas uma característica, um ponto de vista que a pessoa tem, né? E, muitas vezes, também não é legal. $\mathrm{E}$, apesar de concordar ou não, que prevaleça o respeito, que prevaleça a amizade, porque, às vezes, é só por uma questão de uma pessoa desrespeitar a outra que já acontece uma tragédia. $\mathrm{E}$ eu, como professora, posso contribuir para mudar a mente dos meus alunos, falando de respeito, de paz (D5).

Consoante a Declaração Universal dos Direitos Humanos (DUDH), compreende-se tolerância como a aceitação da diversidade das culturas e a harmonia pela diferença, sendo não somente um dever, mas também uma necessidade política, 
pois somente ela é capaz de disseminar a cultura da paz. Para Fischmann, a escola tem a missão de educar para a tolerância e de incentivar a sua prática por meio da “[...] valorização da diversidade humana e da busca de viver com o outro de forma respeitosa, saudável, pautando a resolução de problemas e desacordos pela via do diálogo" (2001, p. 70), tal como foi explicitado por D4 e D5.

\section{Categoria 3: currículo e formação do professor na educação para diversidade e direitos humanos}

Os discursos de alguns docentes transpareceram que a pouca e superficial abordagem das temáticas diversidade e direitos humanos em suas aulas resultava da ineficiência da formação inicial, da ausência de formação continuada e da estrutura dos sistemas de ensino. D3 foi quem discorreu com maior clareza sobre esses aspectos, ao inferir que procurava, nas aulas de História e de Sociologia, trazer as discussões para a sala de aula, deparando-se, porém, com inúmeras dificuldades, desde a ausência de material didático até a falta de formação e de incentivo:

Mas eu devo dizer, como crítico que sou, que não é nada muito profundo, não (a sua abordagem), e eu digo o porquê: não temos formação para aprofundar esses assuntos, trazendo para a realidade dos alunos mesmo, nem temos material didático para isso. Não tem estímulo mesmo, simplesmente não é importante dar ao aluno uma noção de direitos humanos nem formá-lo para respeitar a diversidade. É por isso que a escola não forma cidadão, forma qualquer coisa, menos cidadão, porque a criatura sai daqui e não tem nem noção dos seus direitos. Eu acho importante, mas o Governo não. E eu sou o quê? Nada (D3).

Apesar da consciência acerca da importância da EDH, a formação do professor apresenta-se como um dos maiores desafios segundo D3. De acordo com Tavares (2007), a formação inicial é realmente deficitária e precisa ser ampliada continuamente. Ainda que a formação inicial seja bastante significativa, é válido ter ciência de que ela se trata de um primeiro e pequeno passo, já que a real EDH é contínua e, ao considerar que a sua finalidade é constituir uma cultura de direitos humanos, deve estar sempre se renovando, dada a mutação acelerada dos tempos (HORTA, 2000).

Ao considerar que a formação do educador irá impactar na sua prática, Magendzo (2006) ressalta a formação de educadores de modo interdisciplinar, pois a interdisciplinaridade irá possibilitar a EDH aos diversos educadores, independentemente da disciplina que lecionem. Para além do aspecto interdisciplinar e de instigar a prática fora do ambiente escolar, Mendonça salienta que a EDH deve estar presente nos “[...] projetos político-pedagógicos, nos regimentos escolares, nos materiais didáticos e pedagógicos, nos processos de gestão democrática e de avaliação, 
devendo ainda orientar a formação inicial e continuada de todos os profissionais da educação" (2013, p. 260).

D4 ponderou que tentava discutir sobre questões cidadãs, mas revelou que sentia dificuldade e que não tinha certeza quanto à eficácia de suas abordagens, pois o ensino dos conteúdos para o Enem parece ser mais valioso:

Eu tento, não sei se consigo. É difícil. A gente não tem formação nem orientação para isso. O mais importante é ensinar, é aprovar no Enem... Mas é preciso. [...] Mas, mesmo assim, eu falo de diversidade, de humanização... Só não sei se vai dar resultado. Só esperando para ver mesmo (D4).

Embora sejam priorizados os conteúdos curriculares voltados aos exames de admissão no ensino superior, "[...] a educação escolar não pode ser reduzida a um produto que se negocia na lógica do mercado; nem ter como referência quase que exclusivamente a aquisição de determinados 'conteúdos', por mais socialmente reconhecidos que sejam” (CANDAU, 2012, p. 721), visto que a educação deve prezar pela cidadania e pela formação de sujeitos de direito.

Para D7, o grande empecilho são as exigências do sistema de ensino, que determinam o estudo de todo o material didático no decorrer do período letivo: "Não tem nem como. É muita exigência para a gente que é professor de uma escola grande. E o tempo não dá também, passa muito rápido, e o livro está lá para a gente estudar". Há o entendimento de que os direitos humanos e a diversidade são temas transversais, não obstante a organização das disciplinas e, por conseguinte, do currículo, com grande quantidade de conteúdos prescritos, não colaborando para que essa transversalidade se efetive, como aponta o seguinte relato:

Não abordo porque não dá. É para ser tema transversal, disso eu sei porque vi na faculdade, mas aqui, na prática, é muito diferente. Na minha disciplina mesmo eu não vejo essa possibilidade. Assim, se a gente tivesse pelo menos incentivo, seria melhor, entende? Mas não tem é nada (D7).

Tomando como base as Diretrizes Nacionais para a Educação em Direitos Humanos (BRASIL, 2013), a formação em direitos humanos deve acontecer por meio de temas transversais. Desse modo, cada instituição de ensino tem autonomia para decidir quais temas serão abordados e como serão tratados em meio aos demais conteúdos curriculares, bem como estimular os profissionais da educação para trabalharem os temas rotineiramente. O ideal, de acordo com o referido documento, é que a formação cidadã se desenvolva a partir de disciplinas já existentes, de maneira que haja interdisciplinaridade, não sendo necessária uma disciplina propriamente voltada a tal finalidade.

Na concepção de Araújo (2008), os temas transversais devem ser os eixos significativos dos sistemas de ensino; nessa concepção de transversalidade, a finalida- 
de da educação não diz respeito aos conteúdos tradicionais. Tais conteúdos são veículos para tratar de alguma problemática do cotidiano, mas o foco é a formação dos alunos. Partindo desse entendimento, os temas da EDH “[...] que tentam responder aos problemas sociais e conectar a escola com a vida das pessoas transformam-se no eixo vertebrador do sistema educativo, em torno do qual serão trabalhados os conteúdos curriculares tradicionais" (ARAÚJO, 2008, p. 195).

\section{Considerações finais}

Partindo da problemática: como os professores do ensino médio trabalham os direitos humanos e a diversidade com as juventudes? $\mathrm{O}$ objetivo da pesquisa foi compreender as percepções de educadores cearenses do ensino médio acerca dos significados de direitos humanos e diversidade, bem como o modo com que as temáticas são trabalhadas na formação para a cidadania das juventudes na suas práticas educativas. Importou, todavia, clarificar o que se entende por juventudes, direitos humanos e diversidade.

A partir da coleta dos dados, da transcrição e da análise das entrevistas realizadas com os 8 docentes participantes da pesquisa, emergiram três categorias para apresentação dos resultados e da discussão: 1) compreensões docentes sobre direitos humanos e diversidade; 2) práticas pedagógicas no ensino em direitos humanos e diversidade; e 3) currículo e formação do professor na educação para diversidade e direitos humanos.

Constatou-se que os educadores possuíam conhecimentos sobre os direitos humanos e a diversidade, embora esses fossem apresentados de modo breve e superficial. No entanto, estes não estavam inter-relacionados às práticas educativas por eles desenvolvidas. Demonstrou-se que as situações em que os direitos humanos e a diversidade eram tratados em transversalidade com os conteúdos curriculares se configuravam exíguas; quando aconteciam, davam-se por meio de discussões orais, que não estimulavam a cidadania, pois não havia articulação da prática docente cotidiana com a EDH.

A hipótese inicial de que atitudes como preconceito, discriminação e intolerância, que emergem corriqueiramente entre os jovens, eram silenciadas pelos professores possivelmente em decorrência da falta de conhecimentos dos docentes e da invisibilidade dessas temáticas no cotidiano escolar foi parcialmente refutada; já que os professores demonstraram conhecimento acerca das temáticas ensejadas direitos humanos e diversidade -, ainda que de maneira fragilizada e pouco crítica. $\mathrm{O}$ obscurecimento à visibilidade dos construtos foi confirmado, em decorrência da 
ausência de conteúdos e de práticas pedagógicas com escopo de trabalhar questões consoantes a diversidade e direitos humanos.

Verificou-se que os professores não estavam obtendo a formação continuada necessária para o devido exercício do ensino em direitos humanos e diversidade. Além disso, o currículo e os sistemas de ensino, ao priorizarem conteúdos exigidos nos exames para o ingresso no ensino superior, não estimulavam uma prática pedagógica enfática para a cidadania e o respeito à diversidade, dada a ênfase nos conteúdos livrescos e a ausência de recursos didáticos para essa finalidade. Ademais, nem todos os docentes se viam comprometidos com tal discussão, acreditando serem responsáveis apenas pela transmissão de conteúdos específicos da disciplina ministrada, silenciando ou negligenciando os conteúdos interdisciplinares. Em consequência dos posicionamentos omissos, tem-se uma educação que contribui para a preservação e a naturalização do desrespeito e da intolerância no que tange às diversidades.

Apesar da quantidade diminuta de professores participantes deste estudo e da impossibilidade de generalização dos resultados, visto que se realizou um estudo qualitativo, o panorama enunciado enseja luz para a necessidade de formação inicial e continuada dos professores do ensino médio, de modo a destacar o compromisso docente com a formação em direitos humanos e diversidade das juventudes como assunto irrefutável para a formação cidadã.

\section{Referências}

ABRAMO, Helena Wendel; LEÓN, Oscar Dávila. Juventude e adolescência no Brasil: referências conceituais. São Paulo: Ação Educativa, 2005.

ARAÚJO, Alexandre Viana. Política pública para juventude: analisando o processo de construção no Brasil. In: CONGRESSO IBERO-AMERICANO DE POLÍTICA E ADMINISTRAÇÃO DA EDUCAÇÃO, 4; CONGRESSO LUSO BRASILEIRO DE POLÍTICA E ADMINISTRAÇÃO DA EDUCAÇÃO, 7, 2014, Portugal. Anais... Portugal: Anpae, 2014, p. 1-14.

ARAÚJO, Ulisses Ferreira de. Pedagogia de projetos e direitos humanos: caminhos para uma educação em valores. Pro-Posições, Campinas, v. 19, n. 2, p. 193-204, 2008.

BARDIN, Laurence. Análise de conteúdo. Lisboa: Edições 70, 2009.

BASOMBRIO, C. Educación y ciudadanía: la educación para los derechos humanos en América Latina. Perú: Ceaal; IDL; Tarea, 1992.

BATISTA, Wilson. As políticas públicas de juventude. In: CONGRESSO NACIONAL DE EDUCAÇÃO - EDUCERE, 9, 2009, Paraná. Anais... Paraná: PUC, 2009. p. 6961-6975.

BRASIL. Constituição de 1988. Constituição da República Federativa do Brasil de 1988. Diário Oficial [da] República Federativa do Brasil, Poder Executivo, Brasília, DF, 5 out. 1988. 
. Direitos da população jovem: um marco para o desenvolvimento. 2. ed. Brasília, DF: Fundo de População das Nações Unidas, 2010.

Diretrizes Nacionais para a Educação em Direitos Humanos. Brasília, DF: Secretaria Nacional de Promoção e Defesa dos Direitos Humanos, 2013.

Lei no 9.394, de 20 de dezembro de 1996. Estabelece as Diretrizes e Bases da Educação Nacional. Diário Oficial [da] República Federativa do Brasil, Poder Executivo, Brasília, DF, 21 dez. 1996.

. Ministério da Educação. Conselho Nacional de Educação. Parecer CNE/CP n. 8, de 6 de março de 2012. Dispõe sobre Diretrizes Nacionais para a Educação em Direitos Humanos. Diário Oficial [da] República Federativa do Brasil, Poder Executivo, Brasília, DF, 30 maio 2012.

. Plano Nacional de Educação em Direitos Humanos. Brasília, DF: Secretaria Especial dos Direitos Humanos, 2007.

CANDAU, Vera Maria Ferrão. Direito à educação, diversidade e educação em direitos humanos. Educação \& Sociedade, Campinas, v. 33, n. 120, p. 715-726, 2012.

. Educação em direitos humanos: questões pedagógicas. In: BITTAR, Eduardo (Org.). Educação e metodologia para os direitos humanos. São Paulo: Quartier Latin do Brasil, 2008. p. 285-298.

. Tecendo a cidadania: oficinas pedagógicas de direitos humanos. Petrópolis: Vozes, 1996.

FIALHO, Lia Machado Fiuza. A vida de jovens infratores privados de liberdade. Fortaleza: UFC, 2015.

FISCHMANN, Roseli. Educação, direitos humanos, tolerância e paz. Paideia, Ribeirão Preto, v. 11, n. 20, p. 67-77, 2001.

FLICK, U. Introdução à pesquisa qualitativa. 3. ed. Porto Alegre: Artmed, 2009.

FRANCESCHINI, Luciene; SILVA, Marta Regina Paulo da; MARQUES, Renata Fernandes Borrozzino. "Me empresta o lápis cor da pele?". "Pele de quem?": descolonizando currículos na educação infantil. Revista Cocar, Belém, v. 11, n. 22, p. 502-521, 2017.

FUNDO DE POPULAÇÃO DAS NAÇÕES UNIDAS - UNFPA. A juventude brasileira no contexto atual e em cenário futuro. Brasília, DF: UNFPA, 2011. GADOTTI, Moacir. Interdisciplinaridade: atitude e método. São Paulo: Paulo Freire, 1999.

GIDDENS, Anthony. As consequências da modernidade. São Paulo: Unesp, 1991.

GOMES, Nilma Lino. Apresentação. Educação e Sociedade, Campinas, v. 33, n. 120, p. 687-693, 2012. ção, 2007.

Indagações sobre currículo: diversidade e currículo. Brasília, DF: Ministério da Educa-

HADDAD, Sérgio. O direito à educação no Brasil: Relatoria Nacional para o Direito Humano à Educação. Curitiba: DhESC Brasil, 2004. 
HORTA, Maria del Mar. Educar em direitos humanos: compromisso com a vida. In: CANDAU, Vera; SACAVINO, Susana (Org.). Educar em direitos humanos. Rio de Janeiro: D\&P, 2000. p. 125-139.

MAGENDZO, Abraham. Educación en derechos humanos: un desafío para los docentes de hoy. Santiago: LOM, 2006.

MAGRI, Cledir Assísio. A educação em direitos humanos: uma abordagem a partir de Paulo Freire. Revista Espaço Pedagógico, Passo Fundo, v. 19, n. 1, p. 44-63, 2012.

MARQUES, Edílio Alexandre Borges. Fundamentos da educação em direitos humanos e diversidade. In: RIBEIRO, Mara Rejane Alves Nunes; RIBEIRO, Getulio Couto (Org.). Educação em direitos humanos: diálogos interdisciplinares. Maceió: Ufal, 2012. p. 85-107.

MCCOWAN, Tristão. O direito humano à aprendizagem e a aprendizagem dos direitos humanos. Educar em Revista, Curitiba, n. 55, p. 25-46, 2015.

MEIHY, José Carlos Sebe Bom; HOLANDA, Fabíola. História oral: como fazer, como pensar. São Paulo: Contexto, 2007.

MENDONÇA, Erasto Fortes. Educação em direitos humanos, diversidade, políticas e desafios. Revista Retratos da Escola, Brasília, DF, v. 7, n. 13, p. 255-263, 2013.

MORGADO, Patrícia. Práticas pedagógicas e saberes docentes na educação em direitos humanos. In: ASSOCIAÇÃO NACIONAL DE PÓS-GRADUAÇÃO E PESQUISA EM EDUCAÇÃO ANPED, 25, 2002, Rio de Janeiro. Anais... Rio de Janeiro: PUC, 2002. p. 1-16.

NASCIMENTO, Maria das Graças. A dimensão política da formação de professores/as. In: CANDAU, Vera; SACAVINO, Susana (Org.). Educar em direitos humanos. Rio de Janeiro: D\&P, 2000. p. $115-124$.

PIOVESAN, Flávia. Concepção contemporânea de direitos humanos. In: HADDAD, Sérgio; GRACIANO, Mariângela (Org.). A educação entre os direitos humanos. Campinas: Autores Associados; São Paulo: Ação Educativa, 2006. p. 11-42.

RAMOS, Aura Helena. Educação em direitos humanos: local da diferença. Revista Brasileira de Educação, Rio de Janeiro, v. 16, n. 46, p. 191-213, 2011.

SACAVINO, Susana. Direitos humanos, reconhecimento e educação. Revista Espaço Pedagógico, Passo Fundo, v. 19, n. 1, p. 9-19, 2011.

. Educação em direitos humanos e democracia. In: CANDAU, Vera; SACAVINO, Susana (Org.). Educar em direitos humanos. Rio de Janeiro: D\&P, 2000. p. 36-48.

SANTOS, Boaventura de Sousa; NUNES, João Arriscado. Introdução: para ampliar o cânone do reconhecimento, da diferença e da igualdade. In: SANTOS, Boaventura de Sousa (Org.). Reconhecer para libertar: os caminhos do cosmopolitismo multicultural. Rio de Janeiro: Civilização Brasileira, 2003. p. 25-68.

SILVA, Aida. Educação para a cidadania: solução ou sonho impossível? In: LERNER, Julio (Org.). Cidadania, verso e reverso. São Paulo: Imprensa Oficial do Estado, 1997. p. 215-222.

SILVA, Roselani; SILVA, Vini Rabassa. Política nacional de juventude: trajetória e desafios. $C a$ derno $C R H$, Salvador, v. 24, n. 63, p. 663-678, 2011. 
SOARES, Marta Genú. Escritos freireanos sobre formação do professor: a construção contínua da ação docente nas experiências latino-americanas. Revista Cocar, Belém, n. 2, p. 207-225, 2016.

TAVARES, Celma. Educar em direitos humanos, o desafio da formação dos educadores numa perspectiva interdisciplinar. In: SILVEIRA, Rosa Maria Godoy et al. (Org.). Educação em direitos humanos: fundamentos teórico-metodológicos. João Pessoa: Universitária, 2007. p. 487-504.

ORGANIZAÇÃO DAS NAÇÕES UNIDAS PARA A EDUCAÇÃO, A CIÊNCIA E A CULTURA UNESCO. Declaração Universal dos Direitos Humanos. Brasília, DF: UNESCO, 1998.

ORGANIZAÇÃO MUNDIAL DE SAÚDE (OMS). Plan y Estrategia Regional de Salud Adolescente. Washington: OPS, 2010. 